\title{
Challenges and opportunities of wireline formation testing in tight reservoirs: a case study from Barmer basin, India
}

\author{
$\operatorname{Ajesh~John~}^{1}$ (D) Ankit Agarwal $^{2} \cdot$ Manoj Gaur $^{1} \cdot$ V. Kothari $^{1}$
}

Received: 26 August 2015/Accepted: 24 May 2016/Published online: 4 June 2016

(C) The Author(s) 2016. This article is published with open access at Springerlink.com

\begin{abstract}
Tight reservoir exploration in Barmer basin has huge potential with possible in place volumes of multi billion barrels in reservoirs across the Mesozoic to Cenozoic stratigraphic levels. These tight reservoirs (permeability in the range of $0.01-10 \mathrm{mD}$ ) are ideal fraccing candidates for commercial production. One of the critical challenges in tight reservoir exploration is early assessment of permeability and reservoir fluid type identification through wireline formation testing (WFT) to determine flow behavior, frac optimization and expected deliverability after fraccing. The most prospective Barmer Hill (BH) and Fatehgarh (FAT) tight formations from the basin have been tested with new 3D radial probe WFT tool providing significant time and cost optimization opportunities. Good quality fluid samples with very low contamination levels were extracted with less rig time and operational costs from very low permeable $\mathrm{BH}$ formation $(0.18 \mathrm{mD} / \mathrm{cP}$ mobility $)$ and FAT formation $(0.35 \mathrm{mD} / \mathrm{cP}$ mobility $)$ in 150 and 200 min respectively. 3D radial probe and dual packer module based WFT job were compared for their efficiencies in similar environment. The results show that $3 \mathrm{D}$ radial probe has less inflation time $(\sim 1 / 5$ th $)$, quick fluid
\end{abstract}

Ajesh John

ajesh.john@cairnindia.com

Ankit Agarwal

AAgarwal8@slb.com

Manoj Gaur

manoj.gaur@cairnindia.com

V. Kothari

v.kothari@cairnindia.com

Cairn India Limited, Gurgaon, Haryana 122011, India

2 Schlumberger India, Navi Mumbai, Maharashtra 400703, India detection $(\sim 1 / 10$ th time $)$, quick and reliable packer deployment, focused fluid flow regime to address the formation heterogeneity and minimum hole sticking issues due to mechanical arms around the probe. In short, 3D radial probe can address both the uncertainties of WFT in tight reservoirs and optimized well testing and frac design for cost effective field development.

Keywords Tight reservoir - Wireline formation testing · Fluid type $\cdot$ Mobility $\cdot$ Contamination

\section{Introduction}

Geoscientists seeking to characterize reservoirs and to steer the field development strategies depend heavily on down hole reservoir fluid analysis and transient pressure evaluation (Ayan et al. 2013). However, fluid identification, pressure estimation and hydrocarbon column delineation can be difficult in complex reservoirs and particularly in the case of tight reservoirs. Down hole fluid testing in the form of wireline formation testers (WFTs) has gone through multiple generational improvements since 1950s especially in the tool design for fluid identification and pressure estimation. WFT consists of several modules and components which can be configured interchangeably depending on the reservoir properties and job objectives. Pressure measurements are conducted with a single probe and sampling applications will require a pump out as well as fluid analyzer module for fluid identification. New versions of the WFT tool uses dual packers (DP) inflated above and below the sample point or area of investigation, to isolate the formation from wellbore fluids and to expose more of the formation for sampling. The next generation WFT tool presents $3 \mathrm{D}$ radial probe configuration with 
capabilities to address many of the hole and formation related challenges. In this paper we will be discussing the challenges of tight reservoir exploration and salient features of 3D radial probe WFT tool with special reference to Barmer basin.

The Barmer basin is the most prolific hydrocarbon rift basin along the west of Rajasthan, India, with more than 7.3 billion bbls of oil and oil equivalent in place discovered so far (Fig. 1). This basin characterized by multiple reservoirs with wide ranging reservoir properties $(<1 \mathrm{mD}$ to $>5 \mathrm{D}$ ) is distributed over the Mesozoic to Cenozoic stratigraphy (Fig. 2). The huge potential of tight reservoirs untapped so far and distributed across the basin is now being explored. Until early 2013, the focus was mainly to find and develop the high quality Fatehargh reservoirs in the northern basin. However, other tighter reservoirs across the basin are now seen as targets to ensure future production sustainability from Barmer basin (Fig. 3). Source Rock maturation and basin modeling of the Basal Barmer Hill Formation source rock suggest that it alone generated 180 billion barrels of oil. Less than $3 \%$ of this generated resource has been found till date (John et al. 2015). Though it is likely that much of the remainder was lost to the surface as the basin was uplifted and inverted, a sizeable quantity may still be in the unexplored areas as the "yet to find' prospective resource. The multi-darcy stacked fluvial channel reservoirs of Fatehgarh (FAT) Formation are restricted to the northern basin. Towards the south, medium
Fig. 1 Barmer basin map with regional geological set up and major hydrocarbon discovery overlays (modified after John et al. 2015)

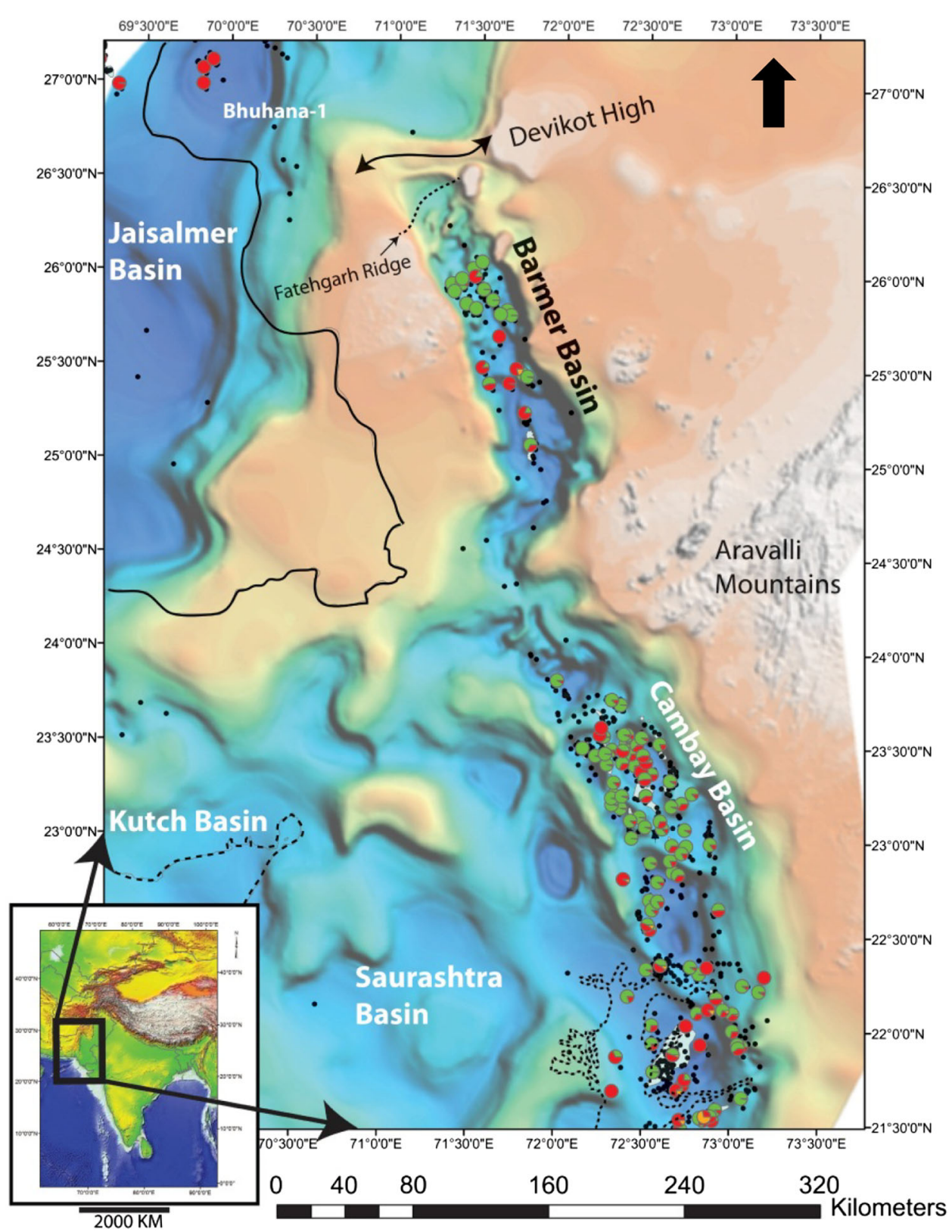




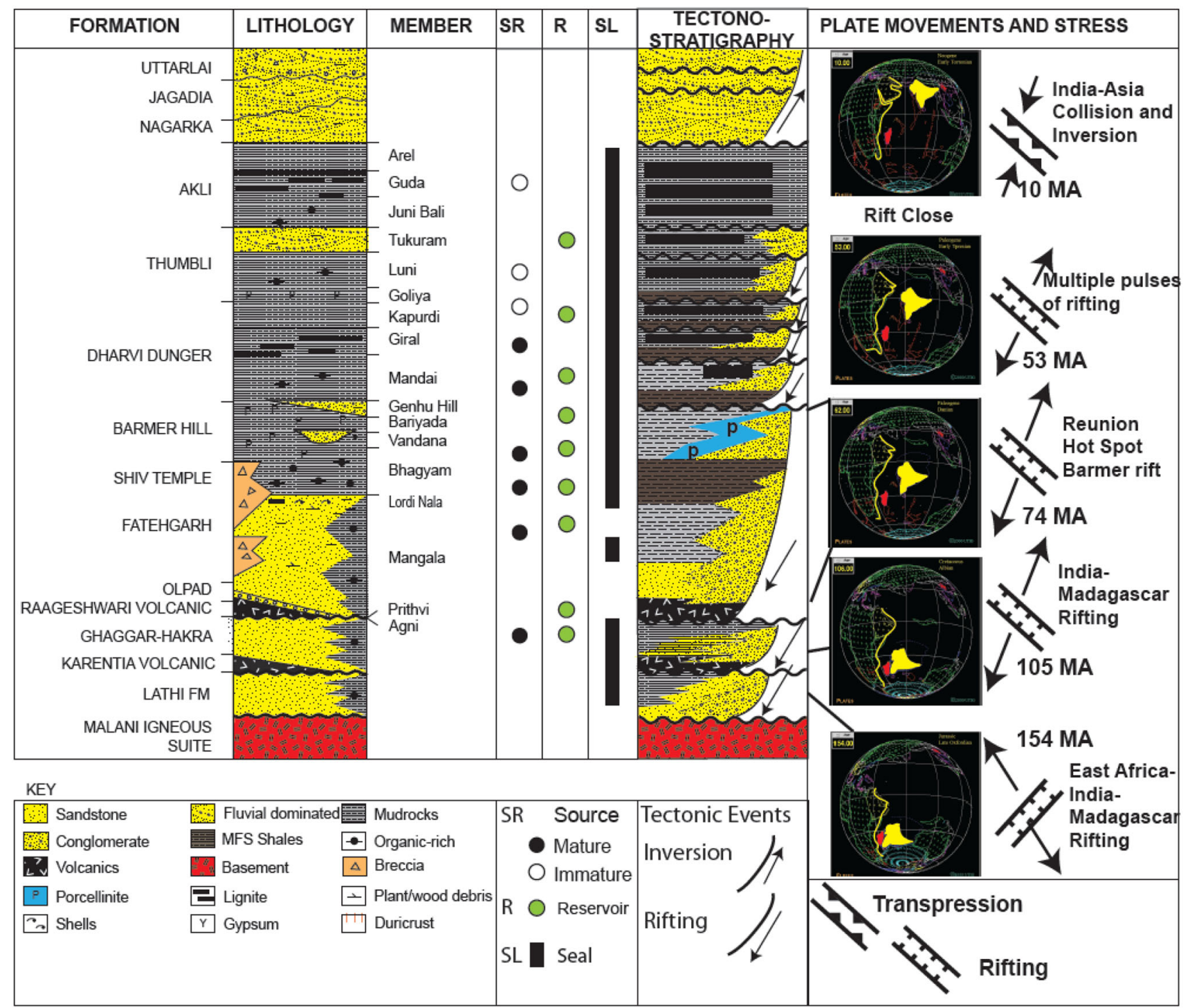

Fig. 2 Detailed stratigraphy of the Barmer basin (after John et al. 2015), summarizing the tectonic evolution, source rocks, reservoirs with hydrocarbon distribution and seals

to low permeability reservoirs are developed throughout the stratigraphic column as porcellanites, turbidites and low energy fan deposits in deeper grabens.

Unlike the conventional reservoirs, tight reservoirs have unique challenges as far as formation testing and reservoir characterization is concerned. The reservoir fluid evaluation takes place using different tools and techniques at different stages of well drilling/logging/testing activities. One of the common methods of formation evaluation is based on LWD/wireline log interpretation. In the case of tight reservoirs, both due to over compaction and/or diagenetic effects, the simple porosity-fluid type relations from conventional reservoirs break down. The high clay and organic matter content create additional complexities for log-based interpretation and evaluation. In our reservoirs high (up to $8 \%$ ) total organic content (TOC) has reported leading to variable matrix densities $(2.5-2.65 \mathrm{~g} /$ cc) across different pay zones. In nutshell a combination of shale with high carbonaceous matter (in general a high resistivity indicator) and shale with variable clay (low resistivity indicator) exhibits a mixed and complex rock behavior particularly in an exploration phase. Moreover, gas shows and gas levels always give mixed responses in tight reservoirs due to either drilling or formation pressure dependent factors. Wireline formation testing (WFT) provides invaluable information about formation fluid and helps to optimize expensive fraccing and testing phases. Wide variation in formation water salinity across the basin, often at short distances, poses serious challenges in resistivity based conventional interpretation. For example, the 
Fig. 3 Comparison of porosity and permeability by facies. a FAT formation and $\mathbf{b} \mathrm{BH}$ formation (re-produced from John et al. 2015). Horizontal lines are $\mathrm{K} / \mathrm{PHI}$ ratios (dashed) and Winland R35 port radii in microns (pittman, 1992). The red lines are hydraulic flow units (HFU) to demarcate the rock types. The red enveloped facies in BH and FAT levels are the tight reservoir targets in the Barmer basin. Most of the turbidite facies (black envelope) of $\mathrm{BH}$ also falls under the tight reservoir category
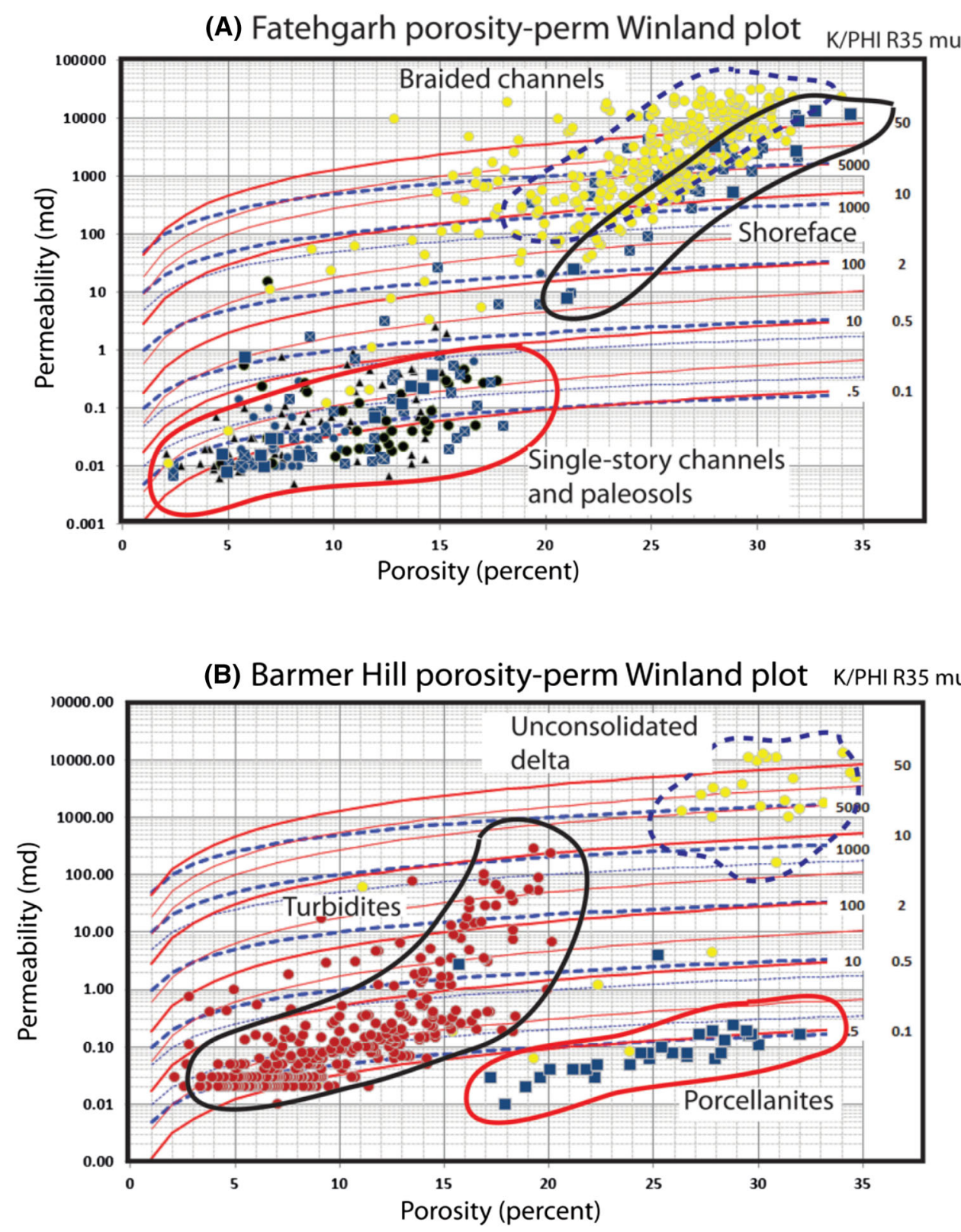

reservoirs with 20-30 $\Omega$ m resistivity produced water on fraccing whereas low resistivity $(<5 \Omega \mathrm{m}$ ) reservoirs tested as oil bearing. The reservoir fluid type and petrophysical signature does not have a strong correlation in most of the tight reservoirs which brings enormous challenges to WFT to optimize the frac job for final well testing, ultimately impacting well results and costs.

\section{DP Versus 3D Radial Probe in Tight Reservoirs}

DP module embedded WFT's are commonly employed in the formation testing of tight reservoirs and significant rig time is consumed for down hole fluid identification and collection. On average, between 42 to $48 \mathrm{~h}$ per well are used for reservoir fluid detection depends on the number of tests and sampling stations with mobilities $<10 \mathrm{mD} / \mathrm{cP}$ using DP tool string. Differential sticking risks are always present in most of the long pumping out stations, and the possibility increases further when multiple reservoirs with high differential pressures are present in the same hole section. The packers in the DP module are normally configured to isolate a $1 \mathrm{~m}$ interval and allowing more formation surface area for testing. Though this design is one of the major advantages of DP assembly for conventional reservoirs, it becomes a major hurdle for tight reservoir testing since a large sump volume needs to be displaced ( $\sim 20-22 \mathrm{~L}$ in a 8.5" hole) before getting the fluid 
breakthrough from the formation. This sump volume displacement will take anywhere between 5 and $8 \mathrm{~h}$ in tight reservoirs depending on the mobility range.

The new 3D radial probe addresses many limitations of formation testing in complex environment and more importantly interval volume issue as in the case of DP module. The design and placement of four large ports spaced evenly on the tool circumference provides a radial flow pattern for reservoir fluids from the formation. This configuration not only increases the efficiency of the cleanup process but also averages out the lithological heterogeneities like laminations and facies variation around the wellbore. The lithological heterogeneities are best understood when the tool is in direct contact with the formation as the tool response can be correlated to the petrophysical logs. The 3D radial probe $(\sim 80$ square inch surface flow area) increases the contact surface area by more than 500 times compared to single probe module, which in dual packer module is not possible as there is no contact between the tool and the formation. The mechanically activated pad design in the radial probe module enables quick deployment of the packers against the station depth and also significantly reduces the tool sticking hazard due to the mechanical arms which can exert back pressure in case of differential sticking situations. Another critical parameter which helps to achieve test success in tight reservoirs is higher draw down. The radial probe specification is rated to give draw down as high as $6000-8000 \mathrm{psi}$ depends on the depth of investigation. This range provides a substantial advantage over any other module available with WFT (2000-3000 psi in case of DP). This paper presents the successful deployment of $3 \mathrm{D}$ radial probe as a
Table 1 Flow modeling parameters for BH formation

\begin{tabular}{ll}
\hline Formation properties & Value \\
\hline Porosity & $12(\mathrm{v} / \mathrm{v})$ \\
horizontal permeability & $0.1(\mathrm{mD})$ \\
Anisotropy (kv/kh) & $0.05(\mathrm{f} / \mathrm{f})$ \\
Max. flow rate & $25 \mathrm{cc} / \mathrm{s}$ \\
Formation pressure & $3000 \mathrm{psi}$ \\
Differential (max) & $2500 \mathrm{psi}$ \\
Invasion & $4 \mathrm{in}$. \\
\hline
\end{tabular}

breakthrough for tight reservoir testing and an alternative for the DP based conventional approach. The objective of this paper is to introduce new possibilities for WFT in tight reservoir exploration to assure successful data acquisition, operational cost optimization and reliable formation evaluation results.

\section{Flow Modeling on 3D Radial Probe Versus DP Sampling}

A modeling exercise has been carried out for different probe types and packer (Kristensen et al. 2014). The same exercise has been carried out for formation properties in the Barmer Hill (BH) reservoirs as mentioned in Table 1. Figure 4 shows the comparison of dual packer and 3D radial probe, the two tools are comparable at low contamination levels $(<5 \%)$, whereas the $3 \mathrm{D}$ radial probe is faster during early cleanup. Modeling for contamination at sand face for 3D radial probe and dual packer is done with
Fig. 4 Contamination comparison between the 3D radial probe and dual-packer inlet (miscible and immiscible model) in $\mathrm{BH}$ formation from Barmer basin
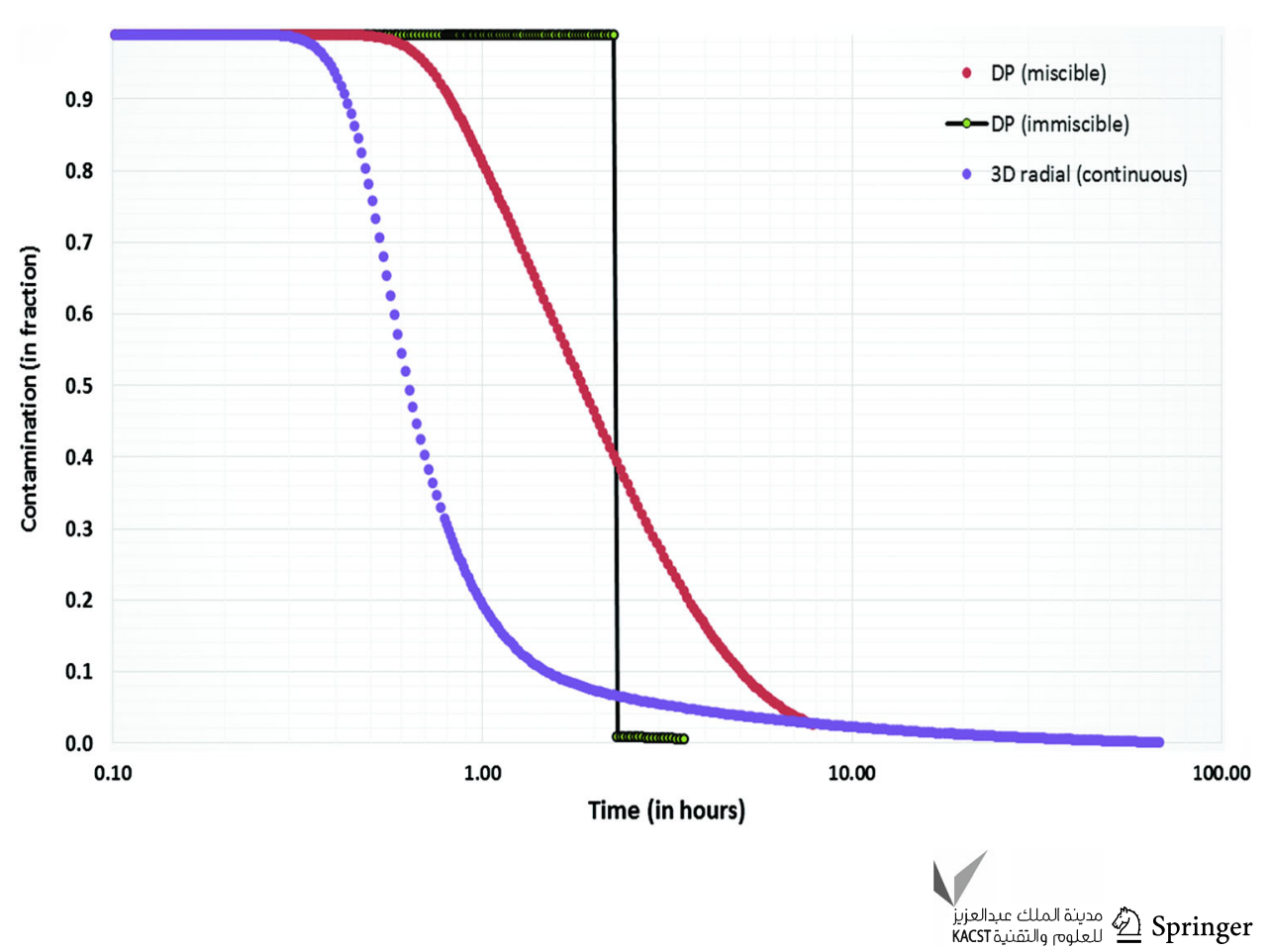


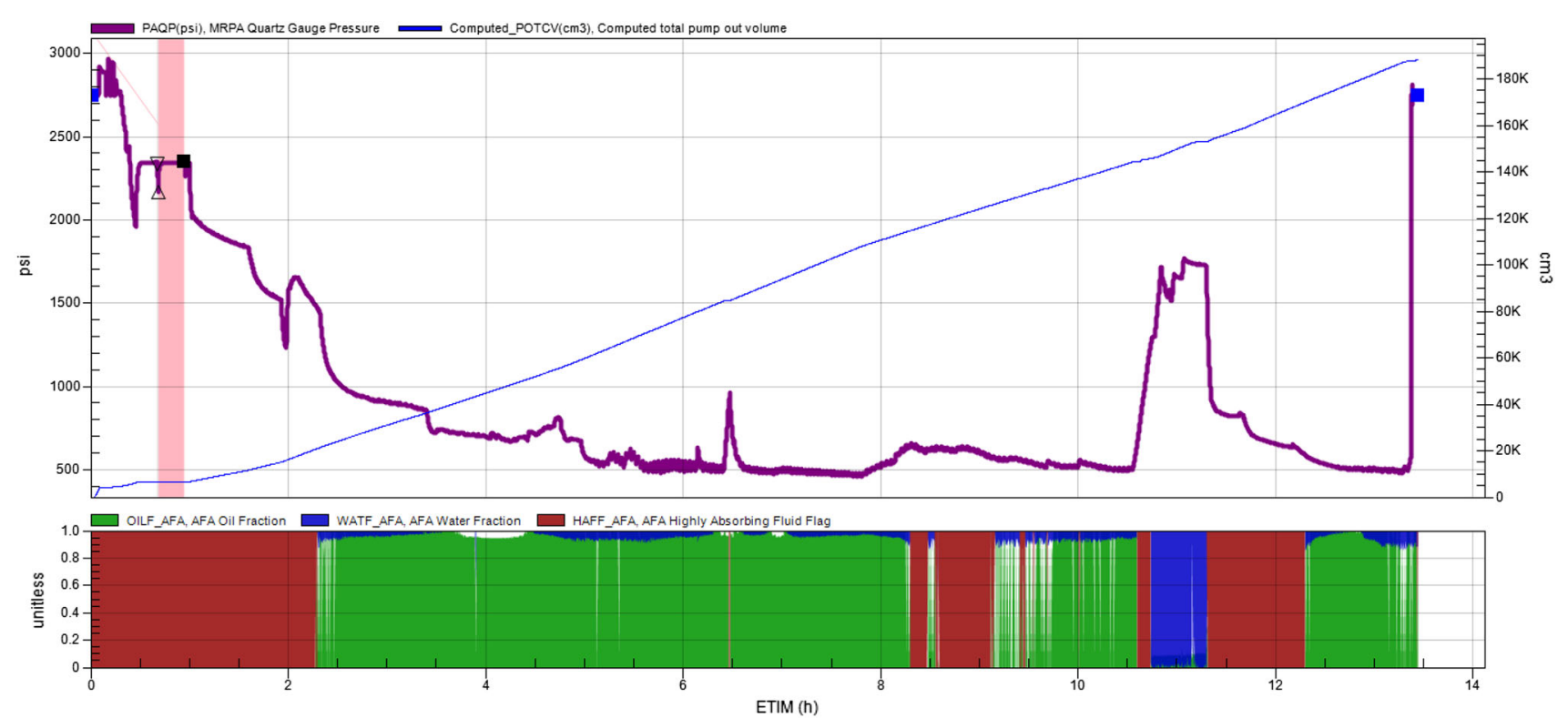

Fig. 5 Pressure time plot for DP module based WFT in $\mathrm{BH}$ formation from the northern part of the Barmer basin. The main plot shows the variation of curves with time (in hours), flow line pressure (in maroon), and volume pumped (in blue) and the secondary plot

precision, however due to the interval volume of dual packer the contamination at tool inlet is not a simple modeling exercise. Segregation and mixing are the two physical phenomenon which are mostly occurring in the wellbore column of a dual packer module. At very low flow rates $(\sim \mathrm{cc} / \mathrm{s})$, segregation phenomenon occurs where the fluid entering the wellbore from the formation settles at the bottom or top of the interval depending on the gravity effects. At very high flow rates $(\sim 40 \mathrm{cc} / \mathrm{s})$ mixing phenomenon occurs where the entering fluid mixes instantaneously with the wellbore fluid column to form one combined mixture. In Kristensen model it is assumed that the fluid entering the wellbore mixes instantaneously with the whole wellbore interval (miscible model in Fig. 4). However in $\mathrm{BH}$, the formation permeabilities are between 0.1 and $1 \mathrm{mD}$ due to which the flow rates during pumping are extremely low $(<5 \mathrm{cc} / \mathrm{s})$. Due to lower flow rate there is sufficient time for segregation in the wellbore, and contamination model with segregation (immiscible model in Fig. 4) shows delayed breakthrough of the formation fluid inside the wellbore. However the actual response of dual packer will be between the miscible and immiscible model and it is difficult to model this due to limited understanding of fluid dynamics in the wellbore.

For long time DP module was employed in WFT testing across the tight reservoirs of Barmer basin. Figure 5 shows one of the stations of DP base WFT in BH formation, where pressure and fluid versus time are represented. The derived mobility for this station was around $\sim 0.1 \mathrm{mD} / \mathrm{cP}$ (below) shows the corresponding change of fluid fraction with time and volume pumped out (in secondary fluid fraction plot, brownOBM Mud/fluid with high solid content, green-OBM filtrate/ hydrocarbon oil, blue-formation water)

and it is seen that close to $2 \mathrm{~h}$ is taken just for mud filtrate/formation fluid breakthrough followed by slow cleanup.

Accomplished simulation run for three cases of formation permeabilities $(10 \mathrm{mD}, 1 \mathrm{mD}$ and $0.1 \mathrm{mD})$ with formation properties as per Table 1 for 3D radial probe (Fig. 6), and following observations were made. Even in $0.1 \mathrm{mD}$ reservoirs, fluid identification was possible in $<1 \mathrm{~h}$ time (will be showing actual examples under case study). No mixing/segregation effects were observed in the 3D radial probe due to zero sump volume. Currently the combined response of pressure flow rates from the 4 probes of $3 \mathrm{D}$ radial probe is measured in the tool; however individual pad flow monitoring can help in estimating critical input about radial anisotropy. This will be more important to prove the capabilities of $3 \mathrm{D}$ radial probe module in simulation environment.

\section{Case Study: Well-1}

As a pilot project, 3D radial probe module was used in WFT program for Well-1 in the northern part of the Barmer basin. Offset well information along with the seismic facies suggested tight reservoir facies mainly in $\mathrm{BH}$ and partly in FAT. Petrophysical analysis (Fig. 7) concluded high porous (10-20 p.u) and low permeable $(0.1-1 \mathrm{mD})$ reservoir characters across the $\mathrm{BH}$ level whereas variable porosities (15-20 p.u) and permeabilites $(0.1-200 \mathrm{mD})$ are modeled 
Fig. 6 3D radial probe simulation result for fluid breakthrough in different permeable conditions $(0.1,0.5$, 1 and $10 \mathrm{mD}$ ) in $\mathrm{BH}$ formation from Barmer basin

Fig. 7 Petrophysical logs from Well-1 plotted with calculated mobility values from 3D radial probe test. The permeability values are derived from the core data transformed using established BH reservoir character
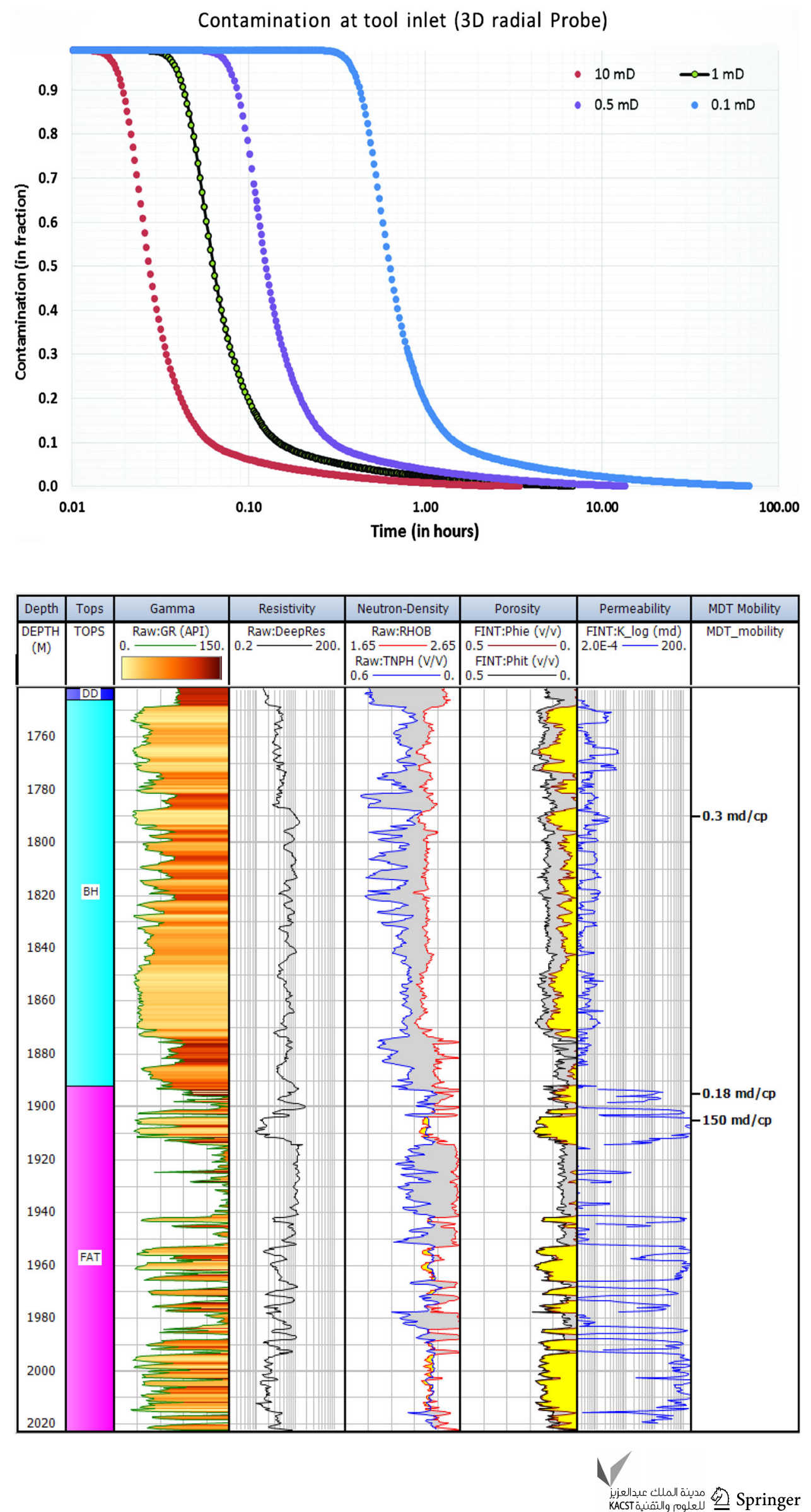

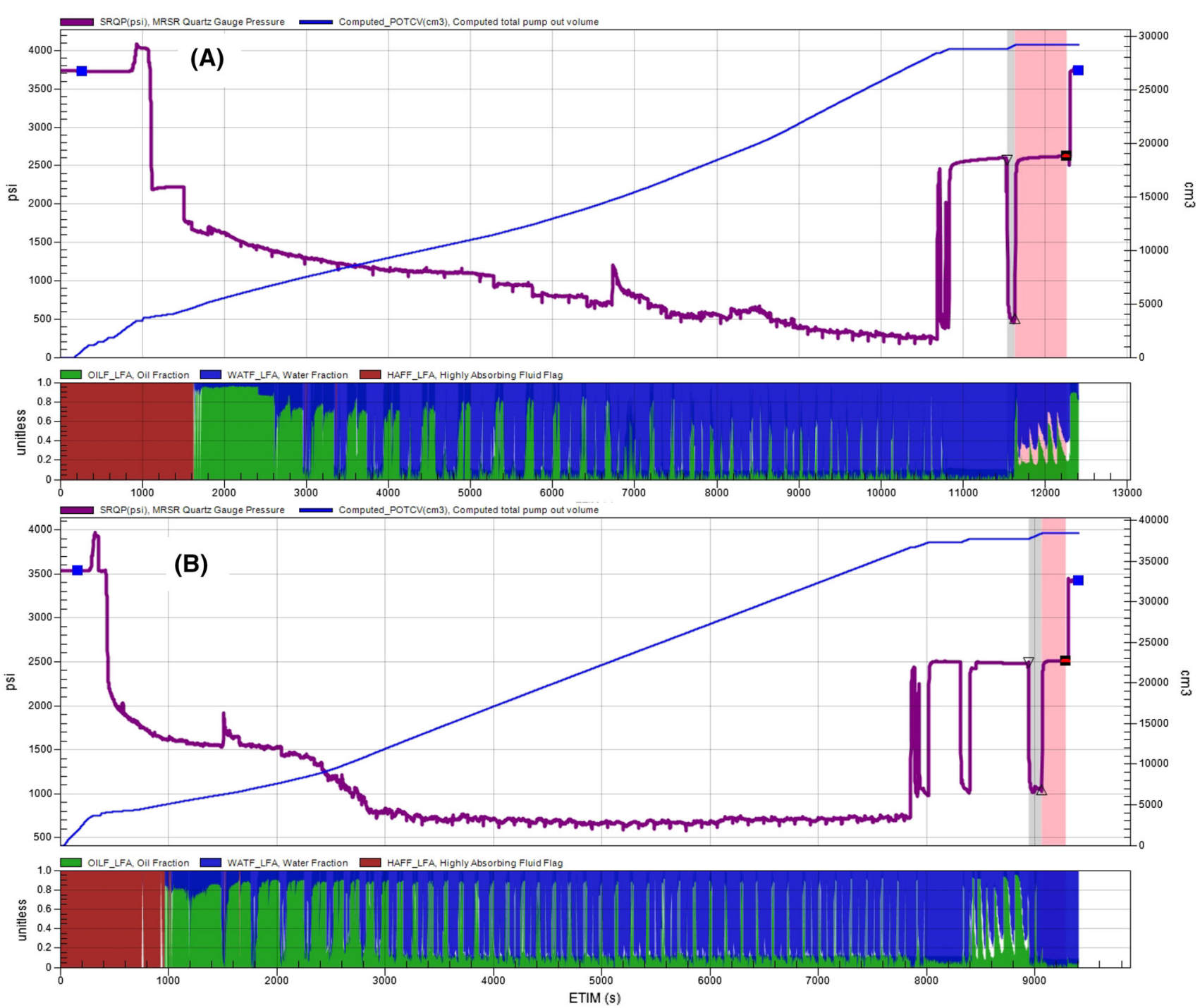

Fig. 8 Pressure time plot for 3D radial probe module based WFT in a FAT formation (station \#1), b BH formation (station \#3), and time is in seconds. Please refer Fig. 5 for curve description

across the FAT level. To test the efficiency of 3D radial probe, this tool was deployed to test the reservoir properties of BH and FAT and results are compared with DP module based testing from similar reservoir levels $(\mathrm{BH})$.

17 stations were tested in $\mathrm{BH}$ and FAT altogether using 3D radial probe module in a single run, out of which 8 stations were in FAT level and remaining 9 points were in BH level. In 3 stations ( 2 in FAT and 1 in BH) stable formation pressures (2450-2550 psi) and stable flow line pressures (1000-300 psi) were recorded. At station \#1 (FAT), packer set and inflation of 3D radial probe completed in $<15 \mathrm{~min}$ and observed the same time lines for all the 17 stations attempted in this well. A first indication of formation fluid in live fluid analyzer (LFA) was detected in $<30 \mathrm{~min}$. After pumping out $27 \mathrm{~L}$ of fluid in $<180 \mathrm{~min}$, minimum contaminated formation fluid sample (water) was collected (Fig. 8a). The mobility values derived from the pump out volume indicated a mobility of $0.18 \mathrm{mD} / \mathrm{cP}$. Though station \#2 (FAT) was not a tight zone $(159 \mathrm{mD} /$ $\mathrm{cP}), 3 \mathrm{D}$ radial probe test was conducted in order to compare the response. First formation fluid indications were observed in $<10 \mathrm{~min}$. Pumped out approximately $60 \mathrm{~L}$ of fluid in $<90 \mathrm{~min}$ and collected a water sample with almost uncontaminated phase. At station \#3 (BH), first formation fluid indication was observed in $<20 \mathrm{~min}$. Pumped out approximately $30 \mathrm{~L}$ of fluid in $<130 \mathrm{~min}$ and collected formation fluid (water) with minimum contamination (Fig. 8b). The derived mobility value against this station was $0.3 \mathrm{mD} / \mathrm{cP}$. A comparison between $3 \mathrm{D}$ radial probe based formation testing from Well-1 and DP based WFT results from several wells belongs to similar reservoirs (BH and FAT) proved huge savings in terms of time per station and more reliable results from these tight reservoir formations (Fig. 9). The entire WFT job through 3D radial 
Fig. 9 Bar plot depicting the average time saving achieved by $3 \mathrm{D}$ radial probe in comparison with DP module from the similar geological and testing environment in Barmer basin

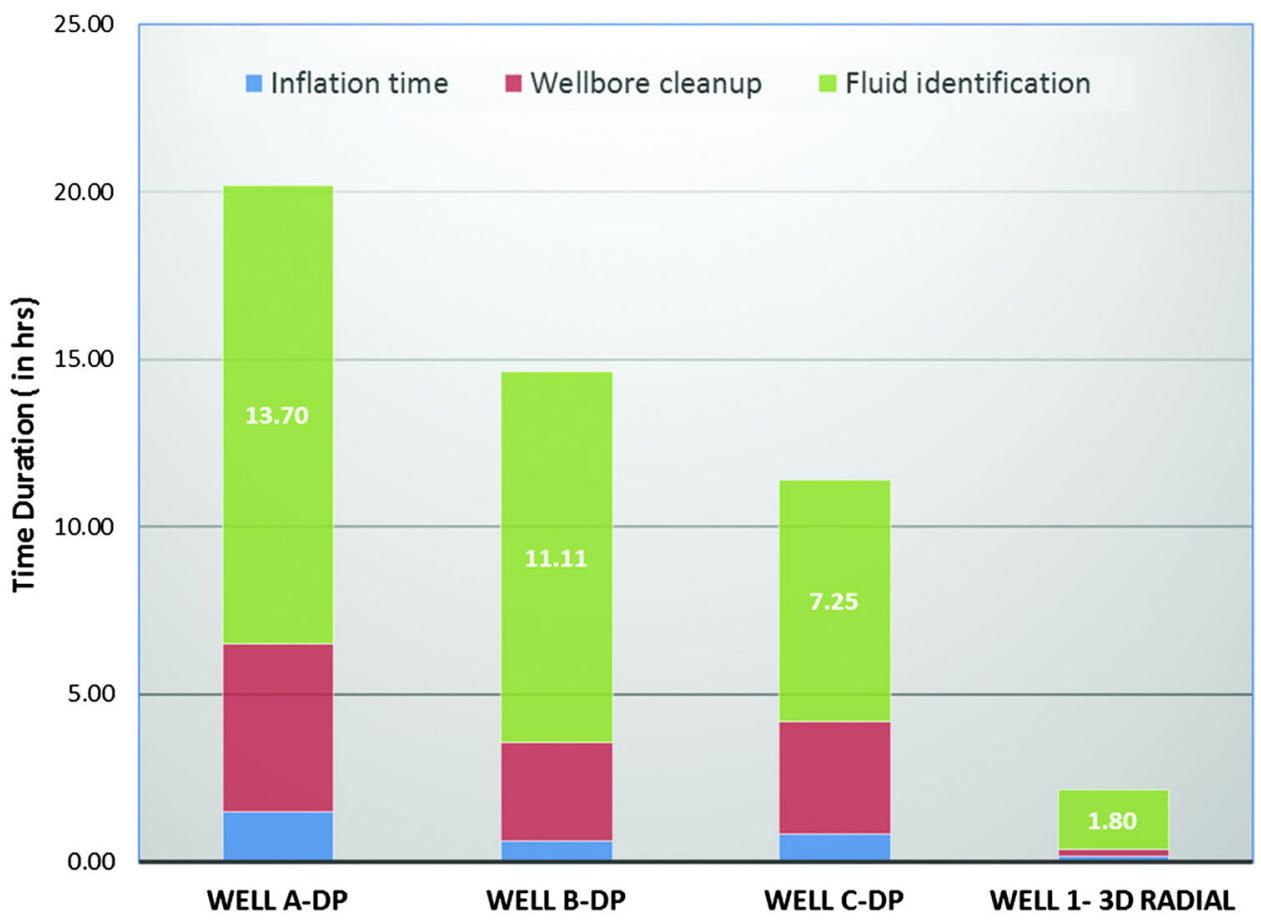

probe in Well-1 has completed in $<14$ h with 17 inflations (stations) and 3 samples.

\section{Discussion}

One of the critical challenges in tight reservoir exploration is formation fluid identification since the conventional petrophysical approach grossly can go wrong as individual tight layers can have unique relationships. As tight reservoirs are fraccing candidates for testing and production, the legitimate information which can finalize the fraccing design in a well is the down hole fluid testing through wireline. Tight reservoir field development plan require stringent development and production designs for optimum expenditures and most of such reservoirs need to be treated and handled with a holistic approach. In Barmer basin, tight reservoir distribution and its prospectivity is definitely promising with huge hydrocarbon reserves in place.

WFT in low permeable and tight reservoirs $(<10 \mathrm{mD})$ are normally performed by using DP module but sump volume cleanup and reliability of the results pose biggest challenge with associated cost factor. In case of 3D radial probe, this critical clean up volume is eliminated with a probe design allowing testing the reservoir fluid in minimum duration with more reliable results. Another important factor is the fluid flow regime, which is very crucial in complex lithological and reservoir heterogeneity conditions. In case of DP module even though more reservoir surface is exposed to the testing environment, the bore hole volume effectively contribute to the flow is not defined.
Whereas the radial displacement of the probe not only introduce more surface flow area but ensure the formation fluid flow from defined borehole volume. The 3D radial probe design help in saving rig time with quick inflation/ deflation processes, quick fluid detection techniques and direct formation fluid pump out capabilities.

In the current geo-political scenario, tight reservoir exploration is facing huge challenges mainly due to reservoir complexities and associated uncertainties and cost factors. In our study area, the results from 3D radial probe wireline testing give immense confidence in the fluid identification part. Though it will solve only part of the overall challenges in the system, the results can significantly reduce the uncertainties in the exploration phase and the overall cost of the project as well. Results from study area shows, this new advanced tool bring the conventional reservoirs and tight reservoirs much closer and comparable in a WFT environment. WFT fluid sampling using normal probes in conventional reservoirs (more than $100 \mathrm{mD}$ ) can take anywhere between 60 and 120 min per station. In study area reservoirs with mobility $<0.35 \mathrm{mD}, 3 \mathrm{D}$ radial probe could collect the sample in 150-200 min.

\section{Conclusion}

In Well 1, both the $\mathrm{BH}$ and FAT tight formations were tested with new 3D radial probe tool through 17 packer inflations. Samples were collected from BH with a mobility of $0.18 \mathrm{mD} / \mathrm{cP}$ in $150 \mathrm{~min}$ (from inflation to deflation) and also from FAT with a mobility of $0.35 \mathrm{mD} / \mathrm{cP}$ in $200 \mathrm{~min}$ 
with minimal contamination. In BH and FAT stations, first fluid indication was obtained in 18 and 27 min respectively after pumping was initiated. The major advantages of $3 \mathrm{D}$ radial probe results from Well-1 in comparison with a DP module in a similar environment is less inflation time (1/ 5th), quick fluid detection since no sump volume to be pumped out (1/10th time), focused fluid flow regime due to 3D radial probe configuration $\left(79.44 \mathrm{in}^{2} \times 4-\right.$ probe surface area), quick and reliable multiple deployment of packer to get a sweet point for fluid extraction, no severe hole sticking issues despite of having several held-ups and over pull during the job. In terms of rig time, 3D radial job got completed in $14 \mathrm{~h}$ in Well-1 against a normal $45 \mathrm{~h}$ DP module based WFT job in a similar environment. Thus, 3D radial probe tool can address many of the current challenges involved with formation testing in tight reservoirs. This can increase the confidence of WFT thus effective well results and optimum frac design and well cost.

Acknowledgments The authors are grateful to Cairn India Limited (CIL) for permission to publish this paper. We acknowledge Stephen Goodlad for his help in the preparation and review of this manuscript.
Our appreciation goes to Ajoy Krishna Bora who contributed to petrophysical description of the study area.

Open Access This article is distributed under the terms of the Creative Commons Attribution 4.0 International License (http:// creativecommons.org/licenses/by/4.0/), which permits unrestricted use, distribution, and reproduction in any medium, provided you give appropriate credit to the original author(s) and the source, provide a link to the Creative Commons license, and indicate if changes were made.

\section{References}

Ayan C, Corre PY, Firinu M, Garcia G, Kristensen MR, O'Keefe M, Pfeiffer T, Tevis C, Zappalorto L, Zeybek M (2013) New dimensions in wireline formation testing. Oilfield Rev 25(1):32-41

John D, Burley SD, Sunder VR, Kothari V, Naidu B, Whiteley NP, Farrimond P, Taylor A, Direen N, Ananthakrishnan B (2015) The discovery of the Barmer basin, Rajasthan, India, and its petroleum geology. AAPG Bull 99(3):433-465

Kristensen M, Ayan C, Chang Y, Lee R, Gisolf A, Leonard J (2014) Flow modeling and comparative analysis for a new generation of wireline formation tester modules. Society of Petroleum Engineers, SPE-169341-MS 